\title{
Aspectos clínicos da ocorrência de dermatofitoses no Estado de Sergipe, Brasil
}

\author{
Clinical aspects of the incident of dermatophytoses in the State of Sergipe, Brazil \\ Aspectos clínicos de la ocurrencia de dermatofitosis en el Estado de Sergipe, Brasil
}

Recebido: 05/08/2021 | Revisado: 13/08/2021 | Aceito: 17/08/2021 | Publicado: 21/08/2021

Edclécia Santos Silva

ORCID: https://orcid.org/0000-0003-4324-6046

Universidade Tiradentes, Brasil

E-mail: ed_edclecia@hotmail.com

Douglas Santos Pinto

ORCID: https://orcid.org/0000-0001-9576-3796

Universidade Tiradentes, Brasil

E-mail: douglaspinto.biomed@hotmail.com

Agenor Gomes dos Santos-Neto

ORCID: https://orcid.org/0000-0003-3698-1456

Universidade Tiradentes, Brasil

E-mail: agenor.gomes@souunit.com.br

Enoque Chaves de Almeida-Junior

ORCID: https://orcid.org/0000-0001-6667-9579 Universidade Tiradentes, Brasil

E-mail: enoque.chaves@souunit.com.br

Tatiane Batista dos Santos

ORCID: https://orcid.org/0000-0002-5807-4614 Universidade Tiradentes, Brasil

E-mail: tatiane.bdos@souunit.com.br

Felipe Santos Rocha

ORCID: https://orcid.org/0000-0003-0749-3189 Universidade Tiradentes, Brasil

E-mail: felipe.srocha@souunit.com.br

Alessandro de França Santos

ORCID: https://orcid.org/0000-0002-8267-3078 Universidade Tiradentes, Brasil

E-mail: alessandro.franca@souunit.com.br

Everton dos Santos Araújo

ORCID: https://orcid.org/0000-0001-6117-7203 Universidade Tiradentes, Brasil

E-mail: everton.daraujo@souunit.com.br Tassiane Silva Santana

ORCID: https://orcid.org/0000-0003-4660-9391 Universidade Tiradentes, Brasil

E-mail: tassiane.silva@souunit.com.br

Josefa Vitória Ribeiro dos Santos

ORCID: https://orcid.org/0000-0001-6387-8388

Universidade Tiradentes, Brasil

E-mail: vitoria.ribeiros@outlook.com

Alice Cristina Santos Bomfim

ORCID: https://orcid.org/0000-0002-1220-3476

Unimed Sergipe, Brasil

E-mail: alice.cristina.bomfim@outlook.com

Lumar Lucena Alves

ORCID: https://orcid.org/0000-0002-0375-1286 Gerald Champion Regional Medical Center, United States of America

E-mail: lalves@gcrmc.org

Daniela Droppa-Almeida

ORCID: https://orcid.org/0000-0002-8154-1030

Universidade Tiradentes, Brasil

E-mail: danieladroppa@gmail.com

Lívia Maria do Amorim Costa Gaspar

ORCID: https://orcid.org/0000-0002-4177-5086

Universidade Tiradentes, Brasil

E-mail: livia.maria@souunit.com.br

Isamar Dantas Oliveira

ORCID: https://orcid.org/0000-0003-2883-5539

Universidade Tiradentes, Brasil

E-mail: isamardantas@gmail.com 


\title{
Resumo
}

As dermatofitoses têm alta prevalência, afetando crianças e adultos, principalmente em regiões tropicais e subtropicais. Os estudos epidemiológicos vêm demonstrando os gêneros Trichophyton, Microsporum e Epidermophyton como os mais comuns que afetam cerca de $20 \%$ da população mundial. Este estudo objetivou analisar o panorama de dermatofitoses no Estado de Sergipe, entre os anos de 2014 a 2017. Para isso, realizou-se um estudo documental, descritivo transversal e prospectivo de detecção dos casos dermatófitos no Estado de Sergipe, diagnósticos micológicos por município de residência, sexo e locais anatômicos, disponibilizados pelo Laboratório Central de Saúde Pública de Sergipe (LACEN) no período de 2014 a 2017. Os resultados das análises mostraram que dentre os 1386 exames micológicos, o número de pacientes do sexo feminino se apresentou significativamente maior em relação ao sexo masculino, no entanto os casos masculinos positivos para dermatofitose foi maior, $51,4 \%$, bem como, a faixa etária entre $0-5$ e 6-10 anos obtiveram os maiores resultados $(18,04 \%$ e $17,07 \%)$. Na verificação dos municípios de residência dos pacientes estudados, nota-se uma relevância para o município de Aracaju. Quanto aos locais de infecção, houve predominância do couro cabeludo (20,73\%), seguido dos membros inferiores $(23,90 \%)$ e unhas $(15,60 \%)$. Diante do exposto, percebe-se que tais resultados mostraram-se relevantes, pois o panorama dessa doença de notificação não compulsória nos municípios do Estado de Sergipe apresentou-se elevadas, enfatizando a necessidade de intervenções que propiciem melhorias na saúde pública e no campo social, sobretudo, por meio da adoção de medidas preventivas e de controle higiênico-sanitário.

Palavras-chave: Dermatofitoses; Epidemiologia descritiva; Infecções; Micoses.

\begin{abstract}
Dermatophytosis demonstrates a worlwide prevalence, especially in children and adults from tropical and subtropical areas. Epidemiological studies have highlighted three main genera as the most common for affecting approximately 20\% of the world population: Trichophyton, Microsporum and Epidermophyton. This study aimed to evaluate the number of cases of dermatophytosis in the state of Sergipe from 2014 to 2017. Therefore, a documentary, crosssectional and prospective study was performed to detect dermatophyte cases in Sergipe, taking into account the following aspects: mycological diagnoses by municipality of residence, sex and anatomical sites. Data was acquired from Central Public Health Laboratory of Sergipe (LACEN) in the same period. The results of the analyzes showed that among the 1386 mycological exams, the number of female patients was significantly higher compared to males, however male cases positive for dermatophytosis were higher, 51.4\%. Another aspect that exhibited greater results was the age group between 0-5 and 6-10 years (18.04\% and 17.07\%, respectively). As for the municipalities of residence of the studied patients, Aracaju demonstrated the majority of the cases. Concerning the infection sites, there was a predominance of the scalp (20.73\%), followed by the lower limbs (23.90\%) and nails (15.60\%). Moreover, it is noted that such results were relevant, as the panorama of this non-compulsory notification disease in the municipalities of the state of Sergipe was elevated. Finally, these results encourage the need for interventions that provide improvements in public health as well as in the social field through the adoption of preventive measures and sanitary actions.
\end{abstract}

Keywords: Dermatophytoses; Descriptive epidemiology; Infections; Mycoses.

\section{Resumen}

La dermatofitosis es muy prevalente y afecta a niños y adultos, especialmente en las regiones tropicales y subtropicales. Los estudios epidemiológicos han demostrado que los géneros Trichophyton, Microsporum y Epidermophyton son los más comunes y afectan aproximadamente al $20 \%$ de la población mundial. Este estudio tuvo como objetivo analizar el panorama de la dermatofitosis en el estado de Sergipe, entre los años 2014 a 2017. Para ello, se realizó un estudio documental, transversal y prospectivo para detectar casos de dermatofitos en el estado de Sergipe, diagnósticos micológicos por municipio de residencia, sexo y sitios anatómicos, proporcionado por el Laboratorio Central de Salud Pública de Sergipe (LACEN) de 2014 a 2017 Los resultados de los análisis mostraron que entre los 1386 exámenes micológicos, el número de pacientes femeninas fue significativamente mayor en comparación con los hombres, sin embargo, los casos masculinos positivos para dermatofitosis fueron mayores, 51,4\%, así como el grupo de edad entre 0-5 y 6-10 años tuvieron los resultados más altos (18,04\% y 17,07\%). Al verificar los municipios de residencia de los pacientes estudiados, se nota una relevancia para el municipio de Aracaju. En cuanto a los sitios de infección, predominó el cuero cabelludo (20,73\%), seguido de las extremidades inferiores $(23,90 \%)$ y las uñas $(15,60 \%)$. Dado lo anterior, es claro que tales resultados fueron relevantes, ya que el panorama de esta enfermedad de notificación no obligatoria en los municipios del estado de Sergipe fue alto, enfatizando la necesidad de intervenciones que brinden mejoras en la salud pública y en el ámbito social, sobre todo, mediante la adopción de medidas preventivas y control higiénico-sanitario.

Palabras clave: Dermatofitosis; Epidemiología descriptiva; Infecciones; Micosis. 


\section{Introdução}

As dermatofitoses são recorrentes em todo o mundo, embora possuam uma maior incidência em países subdesenvolvidos, com estimativa de que $25 \%$ da população mundial são acometidas por alguma infecção fúngica na pele a cada ano (Cock \& Van Vuuren, 2020; Xiao et al., 2019). Segundo estimativas da Organização Mundial da Saúde (OMS), presume-se que existirão em 2025, cerca de 1,2 bilhões de indivíduos com mais de 60 anos acometidos acarretando prejuízos econômicos na área da saúde (Khurana; Sardana \& Chowdhary, 2019; Heinen et al., 2019; Brasil, 2016).

No Brasil entre $10 \%$ e $15 \%$ da população humana já foi diagnosticada com alguma infecção fúngica, sobretudo, dermatófitos. No Nordeste, devido à alta prevalência das dermatofitoses, existem diferentes linhagens fúngicas que se diferenciam de região para região, devido às alterações populacionais e de costumes. Destaca-se, desse modo, os dermatófitos de perfil epidemiológico, onde vem sofrendo mudanças com o passar do tempo (Maranhão et al., 2019). Essas variações acabam dificultando a identificação microscópica e morfológica desses fungos, acarretando muitas vezes um tratamento ineficaz que leva ao aumento dos casos diante das infecções recorrentes (Silva-Rocha; Azevedo \& Chaves, 2017).

As infecções fúngicas denominadas de dermatofitoses são micoses superficiais causadas por fungos responsáveis por infecções na pele, sendo a maioria das infecções causadas por fungos que atinge principalmente indivíduos com sistema imunológico comprometido (Mahboubi \& Kazempour, 2015). Esses fungos podem ser divididos em nove gêneros diferentes, sendo eles: Trichophyton, Epidermophyton, Nannizzia, Microsporum, Lophophyton, Arthroderma, Ctenomyces, Guarromyces e Paraphyton. Dentre esses, os que mais acometem os humanos são os Trichophyton, Microsporum e Epidermophyton. O subgrupo de dermatófilos queratinofílicos tem a capacidade de utilizar a queratina presente na pele, cabelos e unhas, como forma de obtenção de seus nutrientes e em consequência pode ocasionar um processo infeccioso nos referidos locais (Mercer \& Stewart, 2019).

Os sinais e sintomas caraterísticos são: coceira, inflamação, descamação e vermelhidão local e, diante dos locais que podem ser acometidos, as enfermidades possuem uma nomenclatura direcionada ao local das lesões, por exemplo: lesões cutâneas dos cabelos/pelos são conhecidas como Tinea Capitis; lesões na pele são conhecidas como epidermofitíases; e lesões nas unhas, são conhecidas como onicomicoses (Cordeiro, 2015). A transmissão se dá através de superfícies contaminadas, com prevalência em locais quentes e úmidos como bordas de piscinas, chuveiros públicos e banheiros (Song et al., 2018). Contato com animais, bem como, fatores climáticos e socioeconômicos são grandes influenciadores para desenvolvimento das dermatofitoses. Outra contribuição para o surgimento desse tipo de infecção é o uso indiscriminado de antimicrobianos que lava a uma diminuição da microbiota protetora deixando o ambiente propício para patógenos oportunistas (Coelho et al., 2020; Ferro et al., 2020; Silva et al., 2018).

Para o estabelecimento de um diagnóstico fidedigno com base nos aspectos clínicos da lesão e, sob confirmação a partir da avaliação por microscopia direta e cultura, torna-se essencial a combinação de alguns fatores determinantes, tais como: localização das lesões e suas características, história pregressa do paciente e exames laboratoriais. Deste modo, para evitar erros no resultado final, os cuidados pré-analíticos com as amostras podem ser determinantes para um diagnóstico preciso e de qualidade como, por exemplo, a utilização de material estéril no ato da coleta, a não utilização de produtos que possam agir como interferentes (pomada, creme hidrante e remédios caseiros) e antissepsia do local antes de iniciar o procedimento de coleta (Lin et al., 2021; Morris et al., 2016).

Perante o exposto, vários métodos de diagnósticos são disponíveis e podem ser tanto com baixa sensibilidade — porém simples e de baixo custo, quanto métodos de alta sensibilidade - que são de alto custo e mais complexos. Sabe-se que, o exame direto é um método de execução mais simples, mas que permite responder de forma rápida se o caso clínico do 
paciente tratar realmente de uma infecção fúngica. Esta técnica é utilizada na maioria dos laboratórios de micologia e pode ser realizada com fragmentos de tecido epitelial, cabelo, unha ou fluidos serosos de lesões às quais são previamente clarificadas com hidróxido de potássio ou outros agentes clarificantes (Bhat et al., 2019; Gnat, Lagowski \& Nowakiewicz, 2020).

Embora a biópsia seja outro método de exame diagnóstico, a cultura de fungos ainda se faz necessária para a identificação definitiva, sendo um complemento valioso para o exame direto da análise histológica por não fornecer identificação ao nível da espécie. Além disso, também é visto diagnóstico por biologia molecular através de PCR (Polymerase Chain Reaction) que pode identificar e distinguir em nível de DNA as diferentes espécies de fungos, sendo considerado um exame de alta sensibilidade (Motamedi et al., 2017; Gnat, Lagowski \& Nowakiewicz, 2020). Diante disso, Begum et al. (2020) enfatizam a importância do reconhecimento e tratamento precoce das micoses superficiais, no sentido de evitar que estas evoluam para as formas mais graves e até mesmo para as mais invasivas. Por isso, quando o paciente busca atendimento médico para verificação de lesões causadas por micoses, subtende-se que há um incômodo pelo constrangimento que estas lesões podem causar. Em virtude disso, um tratamento prescrito mediante características clínicas pode resultar em danos severos e, ao considerar o agente etiológico causador dessas lesões, ele pode ser resistente às medicações prescritas (Costa-deOliveira \& Rodrigues, 2020; Gupta et al., 2021). A realização de um tratamento adequado pode ser o diferencial determinante na recuperação do tecido lesado, considerando que os espectros de ação dos medicamentos antifúngicos podem levar a falhas no tratamento (Aneke, Otranto \& Cafarchia, 2018).

Deste modo, Kaul, Yadav e Dogra (2017) relataram que para uma escolha adequada e satisfatória do tratamento das dermatofitoses é necessário a identificação da espécie envolvida para obter uma boa eficácia, segurança e biodisponibilidade dos fármacos $\mathrm{O}$ tratamento pode ser tópico, sistêmico ou associando ambas as formas, através de duas classes principais de agentes antifúngicos: os azóis e as alilaminas, juntamente com griseofulvina, ciclopirox e tolnaftato. Esses estão disponíveis nas formas de administração oral e tópica. Os antifúngicos da classe azol incluem imidazóis tais como bifonazol, clotrimazol, econazol, cetoconazol, luliconazol, miconazol, sertaconazol e tioconazol; e triazois tais como fluconazol, isavuconazol, itraconazol, posaconazol, ravuconazol, voriconazol e lanoconazol. Por outro lado, os antifúngicos alilamina, por sua vez, incluem amorolfina, butenafina, naftifina e terbinafina (Rezaei-Matehkolaei et al., 2018; Al-khikani et al., 2021).

Em adição, as dermatofitoses não são consideradas doenças de notificação compulsória obrigatória, tornando-se indispensável estudos epidemiológicos relacionados a temática em questão. Diante desses pressupostos, o estudo tem como objetivo analisar o panorama de dermatofitoses no Estado de Sergipe, atualizando a literatura regional e, deste modo, contribuir para o conhecimento sobre dermatofitoses, no que diz respeito aos aspectos clínicos desse quadro patológico.

\section{Metodologia}

\subsection{Aspectos éticos}

A execução da pesquisa teve início após aprovação do Comitê de Ética em Pesquisa (CEP) em seres humanos da Universidade Tiradentes (UNIT), através da obtenção do parecer com o número de protocolo 2.393.170. Para tanto, os estudos aqui realizados atendem aos fundamentos éticos e científicos específicos.

\subsection{Obtenção dos dados e análise}

Trata-se de um estudo documental, descritivo transversal e prospectivo de deteçãa dos casos de dermatófitos no Estado de Sergipe. Para Pereira et al. (2018) a coleta desse tipo de dado refere-se a um método quantitativo e seu emprego objetiva realizar previsões de algum fenômeno em estudo na área da saúde. A Unidade da Federação selecionada está localizada no Nordeste brasileiro, sendo composta com 75 municípios, divididos em 7 regiões de saúde e em 13 microrregiões. 
Segundo dados do IBGE (2020), ocupa uma área territorial de 21.938,184 km² com população estimada de 2.318 .822 habitantes.

As amostras clínicas foram obtidas de pacientes atendidos no Laboratório Central de Saúde Pública de Sergipe (LACEN), no período de 2014 a 2017, sendo que neste período houve ausência de algumas informações referente aos meses em que não foram realizados testes micológicos para dermatofitoses pelo LACEN. Dos pacientes, foram registrados todos os casos correspondentes aos diagnósticos micológicos positivos, negativos e dados epidemiológicos tais como, sexo, idade, município de origem e os gêneros e espécies dos dermatófitos identificados.

A partir dessa amostra documental a tabulação dos dados foram organizados em forma de planilhas contendo todas as informações epidemiológicas utilizando o Excel@. O programa estatístico utilizado foi o GraphPad Prism 6.01 para calcular as variáveis e a criação gráfica dos dados.

\section{Resultados e Discussão}

Durante os meses março e abril de 2018 foram realizadas análises nos prontuários de amostras processadas no LACEN, estas amostras eram provenientes dos últimos 3 anos (2014-2017). Esta instituição é responsável por desenvolver e executar políticas de assistência laboratorial bem como ações de diagnóstico, pesquisa e controle da qualidade de produtos e serviços no Estado de Sergipe.

Após análise dos registros no LACEN, um total de 1386 exames micológicos foram realizados no período de 3 anos, sendo que $1182(85,2 \%)$ foram negativos e $204(14,7 \%)$ positivos. No estudo realizado em comparação aos gêneros, o sexo feminino apresentou maior relevância em relaçao a realizaçao dos exames, onde um total de 827 mulheres para 559 homens. No entanto, apresentou menor decorrencia de dermatofitoses em relaçao aos homens, apresentando um total de 48,5\% dos exames positivos em comparaçao aos $51,4 \%$ de homens positivados para dermatofitose. Ao se comparar com a literatura, Farjado et. al (2017), demonstrou em sua pesquisa que, dentre uma população de 131 indivíduos, foi visto que houve predominância nas mulheres (54,9\%), seguida pelos homens (45,1\%). No entanto, segundo pesquisas de Silva et al. (2018), as dermatofitoses foram mais frequentes em pacientes do sexo masculino, registrando 140 (55,5\%) casos das 252 amostras analisadas. Indicando que não há uma correlação entre a dermatofitoses e gênero.

$\mathrm{Na}$ comparação entre as idades de todos os indivíduos que realizaram os exames, foi observado que houve maiores registros de exames micológicos nas faixas etárias de 46 a 50 e 51 a 55 anos respectivamente (Figura 1, linha cinza). No entanto, levando em consideração somente os positivos, nota-se que as faixas etárias de 0 a e 6 a 10 anos foram mais incidentes (Figura 1, linha preta). 
Figura 1. Faixa etária dos indivíduos que realizaram exames micológicos no LACEN no período de 2014 a 2017. Em cinza estão os exames realizados e em preto apenas os positivos.

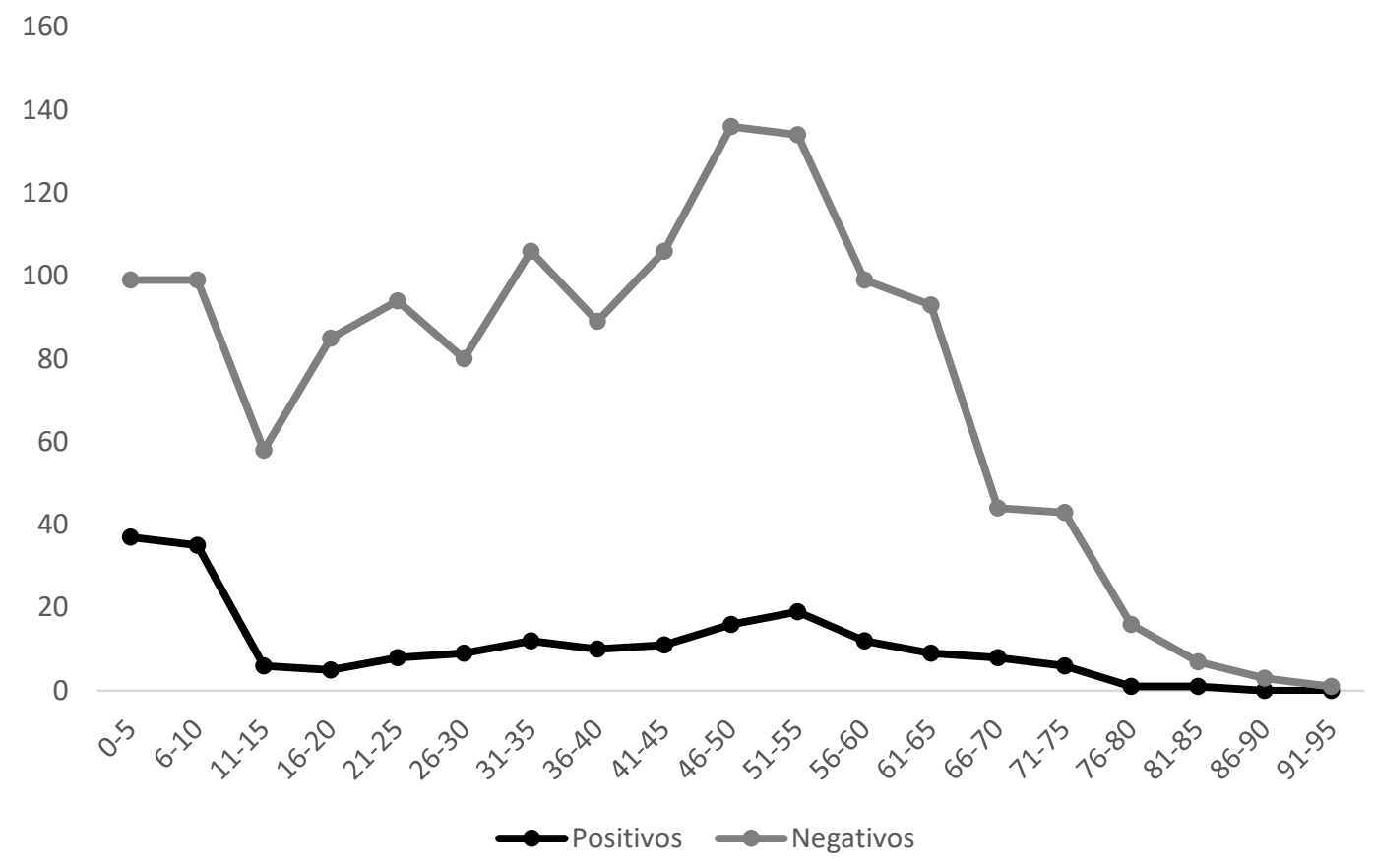

Fonte: LACEN (2018).

Buscando justificar a prevalência dos casos positivados nas faixas etárias de 0 a 5 anos e 6 a 10 anos, Silva (2019) afirma que as crianças que frequentam a escola ou que tenham animais de estimação em casa, estão mais expostas a doença, tendo em vista que ambas as situações favorecem as condições para transmissão de infecções micológicas. Somado a isso, a pesquisa de Lana et al. (2016), relatou que o maior público atingido por dermatófitos são crianças de até 12 anos, não existindo, dessa forma, semelhança com os resultados demonstrados por Farjado et al. (2017), onde relatou que a maior incidência de casos positivos para dermatofitoses foi em indivíduos com idades de 61 a 70 anos.

Não obstante, Araújo (2018) relatam que a faixa etária mais acometida pela infecção no Estado de Alagoas, foi predominantemente 51 a 60 anos, havendo assim, uma dessemelhança com os dados encontrados na presente pesquisa, enquanto Ferro et al. (2020) registrou $74(38,34 \%)$ na faixa etária $>50$ anos e $36(18,35 \%)$ entre 31 a 40 anos, tendo essas faixas etárias como os maiores achados. Essa doença tem uma maior preferência por crianças, devido a maior exposição desse público aos fatores de risco, tais como a precariedade dos hábitos higiênicos, contato direto à areia e com animais domésticos e, em virtude da aglomeração em centros recreativos como creches e escolas (Jesus \& Sousa, 2020).

Com vista nesse cenário, torna-se evidente a necessidade de potencializar as análises e investigações da frequência de agentes etiológicos das dermatofitoses em parques e centros recreativos, sobretudo nas grandes cidades, considerando que são ambientes com grande circulação de crianças e que podem propiciar um ambiente favorecedor a contaminação por agentes causadores de micoses e bactérias.

Para compreender a ocorrência da dermatofitose no Estado de Sergipe, é necessário avaliar o quantitativo de casos confirmados em todos os municipios do Estado, com o intuito de auxiliar as autoridades governamentais para que seja possível traçar intervenções que proporcionem a reduzação do número de casos dessa doença (Figura 2). 
Figura 2. Casos de dermatofitoses por região no Estado de Sergipe. A) Mapa ilustrativo do Estado de Sergipe separado por regiões e com os respectivos caso positivos de dermatofitoses por região. Alguns municípios não estiveram presentes nos prontuários analisados e estão descritos na legenda da figura. B) Quantitativo de casos positivos de dermatofitoses por municípios, municípios ausentes apresentaram valores iguais a 1 ou 0 para dermatofitoses, ou não apresentaram exames realizados nos prontuários.

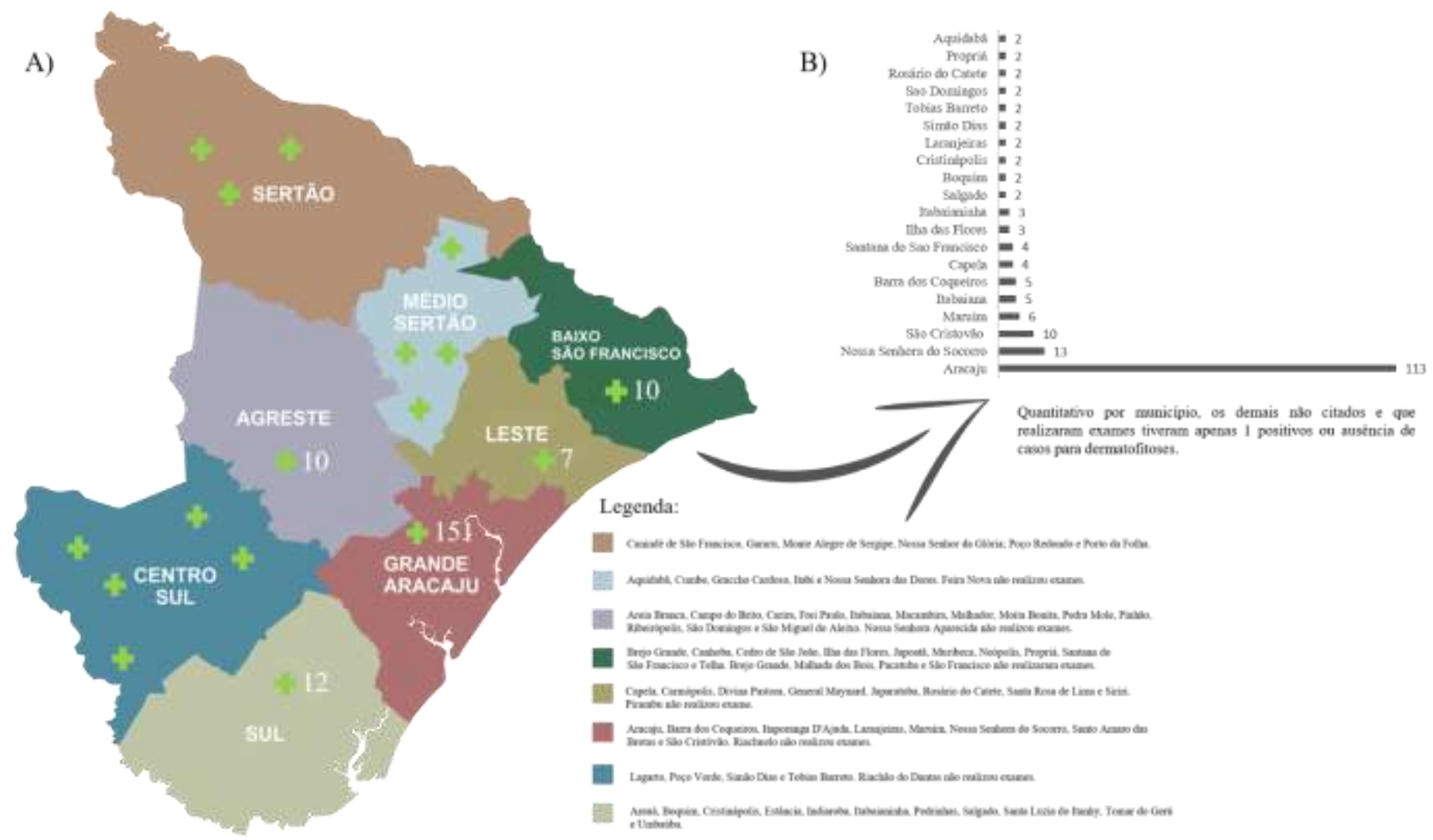

Fonte: LACEN (2018).

Na verificação dos municípios de residência na Figura 2, observa-se uma considerável relevância para o município de Aracaju (57\%), em sequência, Nossa Senhora do Socorro (10\%) e São Cristóvão (4,6\%) em relação aos demais municípios demonstrados. Segundo dados fornecidos pelo IBGE em 2020, o município de Aracaju tinha uma população estimada de 664.908 pessoas e por se tratar de uma região metropolitana e com maior circulação de pessoas, pode-se justificar o fato de ter sido a região com o maior quantitativo de casos confirmados em todo o Estado de Sergipe.

A capital de Aracaju, quando comparada aos demais municípios, também possui o maior número de parques e praças, tornando o acesso da população, sobretudo às crianças, maior nesses locais, as quais acessam para determinadas atividades de lazer. Por manter contato direto com o solo possivelmente contaminado, o que pode configurar uma fonte de contaminação para fungos e parasitas causadores de doenças, tem-se a necessidade de avaliar a qualidade ambiental de parques, visto que possui grande importância à saúde pública (Jesus \& Souza, 2020; Bernardi et al., 2009).

Analisando-se a relação entre o local de infecção com o agente etiológico, observa-se que as regiões acometidas pelas dermatofitoses foram, respectivamente o couro cabeludo com 63 (30,73\%) casos, seguido dos membros inferiores 49 $(23,90 \%)$ e unhas $32(15,61 \%)$, como apresentados na Figura 3. 
Figura 3. Relação dos locais de lesões acometidos em pacientes com resultados positivos para dermatófitos residentes do Estado de Sergipe no período de 2014 a 2017.

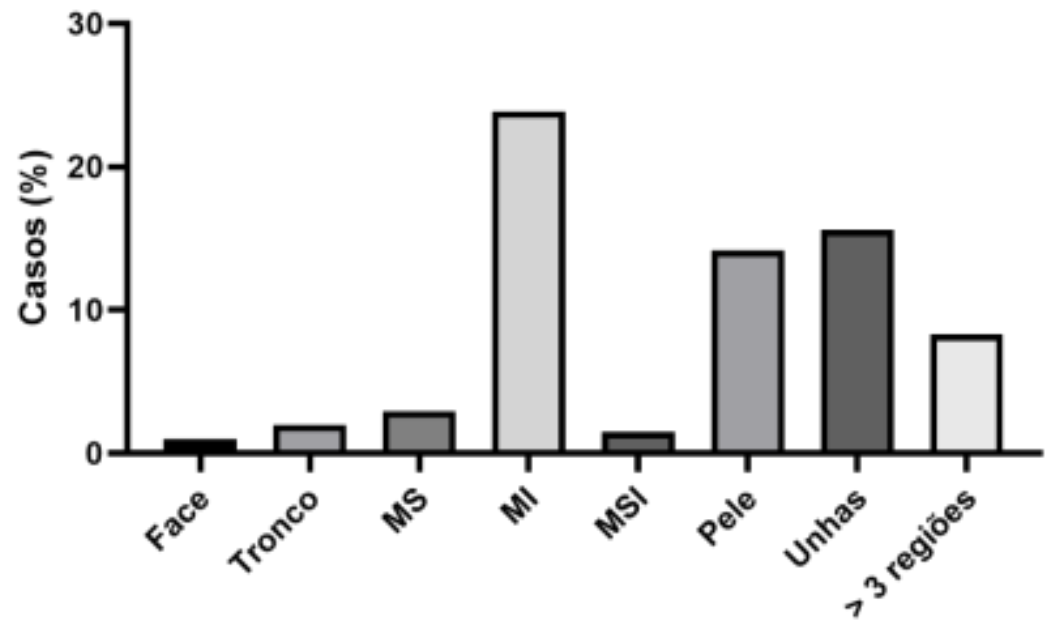

Legenda: MS= Membro Superior; MI= Membro Inferior; MSI= Membro Superior e Inferior. Fonte: LACEN (2018).

As dermatofitoses são classificadas de acordo com a localização anatômica da lesão causada pelos fungos e estão relacionadas também às infecções por Tínea. Nessa perspectiva, as lesões geralmente são superficiais, mas com bordas descamativas e com características de formato circular, pruriginosas e eritematosas. Denomina-se a área como Tínea ou Tinha, sendo caracterizadas como Tínea corporis (lesões na pele), caracterizadas com bordas definidas, descamativas, pruriginosas e eritematosas, enquanto a Tínea capitis (couro cabeludo) tem-se em soma, placas de alopecia (Rodrigues; Tomimori \& Mendonça, 2010).

A Tínea pedis (pés), por sua vez, são definidas por lesões agudas que acometem os espaços interdigitais, causando mau odor, maceração e prurido, principalmente nas pessoas que fazem uso regular de sapatos fechados. Podendo também ser acometida pela Tínea mannum (mãos), barbae (barba) ou faciae (face), sendo influenciadas pela temperatura, condições socioeconômicas e imunidade do hospedeiro (Mezzari et al., 2017).

Não obstante, em determinadas situações que envolvem o estado imunológico do hospedeiro e a espécie do fungo, os dermatófitos podem invadir e colonizar camadas mais profundas da pele, os quais podem ocasionar o granuloma tricofítico, micetoma dermatofítico e a reação dermatofítica, caracterizadas pelos três quadros clínicos desencadeados pelo agravamento da doença (Sidrim \& Rocha, 2012).

Em concordância, as infecções por tinea capitis apresentam as maiores notificações, com uma representação mais incidente, o que não entra em acordo com as informações de pesquisa disponibilizadas por Silva (2019), onde mostrou que os sítios anatômicos mais infectados foram os dedos (24\%), e esta representação total de locais lesionados por dermatófitos, demonstra a variedade de lugares que podem ser acometidos por estes fungos. Em suma, Ferro et al. (2020) também observaram que os locais mais acometidos pelo Trychophyton rubrum foram a pele com 52 e unhas 46 . Enquanto o couro cabeludo apresentou 15 casos em resposta à infecção pela espécie tonsurans e 6 casos pelo Microsporum canis.

Na Figura 4, têm-se as principais espécies identificadas no estudo, tendo o Trichophyton rubrum como agente etiológico mais incidente, com 131 (63,9\%) casos, enquanto o Trichophyton tonsurans apresentou 26 (12,7\%) e o Trichophyton mentagrophytes obteve 22 (10,7\%). Em soma, a espécie Microsporum canis registrou 20 (9,85), seguido do Microsporum gypseum com 5 (2,4\%), enquando o Trichosporon asahii apresentou somente 1 (0,5\%) caso das 204 amostras obtidas na pesquisa. 
Figura 4. Espécies registrados pelo LACEN em pacientes positivados para dermatófitos residentes do Estado de Sergipe entre 2014 e 2017.

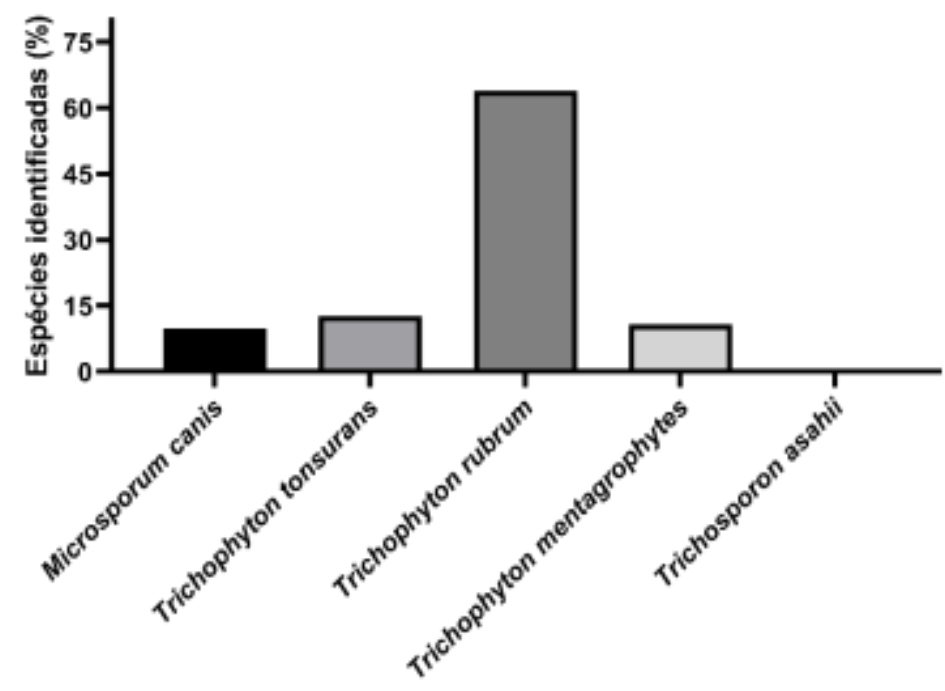

Fonte: LACEN (2018).

Foi demonstrado como o agente etiológico mais prevalente o Trichophyton rubrum $(63,90 \%)$, contudo, essa espécie por se apresentar como cosmopolita pode causar infecções em demais sítios anatômicos. Em estudo desenvolvido por Casanova em 2018, mostraram também que o Trichophyton rubrum (50,7\%), foi a espécie principal que causou mais infecções na população estudada com sessenta e sete pessoas. Por outro lado, pesquisas realizadas por Ribeiro (2015), demonstraram que houve maior representação de Trichophyton rubrum $(81,2 \%)$ dentre os resultados positivos, seguido de Trichophyton mentagrophytes (9,9\%) e Trichophyton tonsurans (3,6\%).

No que se refere aos dermatófitos, o Trichophyton dominou os quadro de infecções, registrando 180 (90,7\%), seguida do Microsporum com 25 (9,3\%). Tais dados ainda corroboram com os achados de Silva et al. (2018), tendo em vista que das 252 amostras, 46 (17,1\%) foram causadas pelo gênero Trichophyton. Ademais, as espécies Trichophyton verrucosum $(0,3 \%)$ e Trichophyton mentagrophytes $(6,3 \%)$ também foram identificadas nas amostras.

Ao comparar os achados com estudos de Morais, Pereira e Cunha (2018), percebe-se que a ausência de Epidermophyton indica uma menor frequência desse gênero. Contudo, os relatos de Oliveira et. al (2015), em França, no interior do Estado de São Paulo, descreve que o Microsporum da espécie canis é incidente e comum em humanos e animais, sendo encontrados em seu estudo 2 casos de 35 indivíduos, representando 5,72\% do total da amostra pesquisada, demonstrando que os gêneros de dermatófitos podem variar entre as regiões do Brasil.

\section{Conclusão}

A presente pesquisa permitiu identificar a ocorrência das dermatofitoses no Estado de Sergipe, bem como, os principais agentes etiológicos e locais de acometimentos no homem. De maneira geral, houve tendência no agente etiológico Trichophyton rubrum, acometendo majoritariamente, crianças na região do couro cabeludo e membros inferiores. As crianças, por sua vez, precisam de uma maior atenção por não se ter informações exatas da extensão do problema, especialmente, por não se tratar de uma doença com notificação compulsória.

Diante do exposto, percebe-se que tais resultados mostraram-se relevantes, pois o panorama dessa doença nos municípios do Estado de Sergipe se apresentaram elevadas. Com isso, mostra-se a importância da realização periódica de 
pesquisas futuras acerca das dermatofitoses, com ênfase nas medidas de prevenção epidemiológica, com o intuito de reduzir a incidência dessa doença e contribuir para melhorias na saúde pública e no campo social, por meio do repasse de informações pertinentes à comunidade.

Vale salientar que a literatura apresenta uma escassez de produções científicas referentes à temática, a qual demonstra que o tema apresenta baixa visibilidade e interesse no meio acadêmico e científico. Diante disso, faz-se necessário levantar tais informações descritivas para que medidas de prevenção e controle higiênico-sanitário sejam levadas em consideração.

\section{Referências}

AL-Khikani, F. H., \& Ayit, A. S. (2021). Major challenges in dermatophytosis treatment: current options and future visions. Egyptian Journal of Dermatology and Venerology, 41(1), 1 .

Aneke, C. I., Otranto, D., \& Cafarchia, C. (2018). Therapy and antifungal susceptibility profile of Microsporum canis. Journal of Fungi, 4(3), 107.

Bernardi, A. C. A., Silva, J. L. M., Souto, A. P. G., \& Almeida, C. C. (2009). Estudo de Fungos Queratinofílicos Geofílicos em Praças Públicas de JaboticabalSP. Revista Brasileira Multidisciplinar, 12(2), 79-88.

Bhat, Y. J., Keen, A., Hassan, I., Latif, I., \& Bashir, S. (2019). Can dermoscopy serve as a diagnostic tool in dermatophytosis? A pilot study. Indian dermatology online journal, 10(5), 530 .

Brasil. Instituto Brasileiro de Geografia e Estatística. 2020. <https://cidades.ibge.gov.br/brasil/se/panorama >.

Begum, J., Mir, N. A., Lingaraju, M. C., Buyamayum, B., \& Dev, K. (2020). Recent advances in the diagnosis of dermatophytosis. Journal of basic microbiology, 60(4), 293-303.

Cock, I. E., \& Van Vuuren, S. F. (2020). A review of the traditional use of southern African medicinal plants for the treatment of fungal skin infections. Journal of ethnopharmacology, 251, 112539.

Coelho, J. L. G., Saraiva, E. M. S., Mendes, R. C., \& de Santana, W. J. (2020). Dermatófito: resistência a antifúngicos. Brazilian Journal of Development, 6(10), 74675-74686.

Cordeiro, L. V. (2015). Perfil epidemiológico de dermatofitoses superficiais em pacientes atendidos em um laboratório da rede privada de João Pessoa-PB.

Costa-de-Oliveira, S., \& Rodrigues, A. G. (2020). Candida albicans antifungal resistance and tolerance in bloodstream infections: The triad yeast-hostantifungal. Microorganisms, 8(2), 154.

Fajardo, A. D., Silva, R. R., Costa, A. P. M., Rossetto, A. L., \& Cruz, R. C. B. (2017). Estudo epidemiológico das infecções fúngicas superficiais em Itajaí, Santa Catarina. RBAC, 49(4), 396-400.

Ferro, L. O., Souza, A. K. P., Rodrigues, D. K. B., Silva, J. R. M., K. W. L. S., Freitas, L. W. S., \& dos Santos Araújo, M. A. (2020). Trichophyton rubrum como principal agente etiológico de dermatofitoses em um laboratório de Maceió-Al. Brazilian Journal of Health Review, 3(5), $13198-13207$.

Gnat, S., Łagowski, D., \& Nowakiewicz, A. (2020). Major challenges and perspectives in the diagnostics and treatment of dermatophyte infections. Journal of applied microbiology, 129(2), 212-232.

Gupta, A. K., Renaud, H. J., Quinlan, E. M., Shear, N. H., \& Piguet, V. (2021). The growing problem of antifungal resistance in onychomycosis and other superficial mycoses. American journal of clinical dermatology, 22(2), 149-157.

Heinen, M. P., Cambier, L., Antoine, N., Gabriel, A., Gillet, L., Bureau, F., \& Mignon, B. (2019). Th1 and Th17 immune responses act complementarily to optimally control superficial dermatophytosis. Journal of Investigative Dermatology, 139(3), 626-637.

Jesus, M. J. S., \& Sousa, Z. L. (2020). Pesquisa de fungos dermatófitos em amostras de solo de parques recreácionais da cidade de Ilhéus, Bahia. Revista Cereus, 12(1), 77-90.

Kaul, S., Yadav, S., \& Dogra, S. (2017). Treatment of dermatophytosis in elderly, children, and pregnant women. Indian dermatology online journal, 8(5), 310 .

Khurana, A., Sardana, K., \& Chowdhary, A. (2019). Antifungal resistance in dermatophytes: Recent trends and therapeutic implications. Fungal Genetics and Biology, 132, 103255.

Lana, D. F.D., Batista, B. G., Alves, S. H., \& Fuentefria, A. M. (2016). Dermatofitoses: agentes etiológicos, formas clínicas, terapêutica e novas perspectivas de tratamento. Clinical and biomedical research. 36(4), 230-241.

Lin, B. B., Pattle, N., Kelley, P., \& Jaksic, A. S. (2021). Multiplex RT-PCR provides improved diagnosis of skin and nail dermatophyte infections compared to microscopy and culture: a laboratory study and review of the literature. Diagnostic Microbiology and Infectious Disease, 115413.

Mahboubi, M., \& Kazempour, N. (2015). The antifungal activity of Artemisia sieberi essential oil from different localities of Iran against dermatophyte fungi. Journal de mycologie medicale, 25(2), e65-e71. 
Maranhão, F. C. A., Oliveira-Júnior, J. B., Araújo, M. A. S, \& Silva, D. M. W. (2019). Mycoses in northeastern Brazil: epidemiology and prevalence of fungal species in 8 years of retrospective analysis in Alagoas. Brazilian Journal of Microbiology, 50(4), 969-978.

Mercer, D. K., \& Stewart, C. S. (2019). Keratin hydrolysis by dermatophytes. Medical mycology, 57(1), 13-22.

Mezzari, A., Hernandes, K. M., Fogaça, R. F. H., \& Calil, L. N. (2017). Prevalência de micoses superficiais e cutâneas em pacientes atendidos numa atividade de extensão universitária. Revista Brasileira de Ciências da Saúde, 21(2), 151-156.

Motamedi, M., Mirhendi, H., Zomorodian, K., Khodadadi, H., Kharazi, M., Ghasemi, Z., ... \& Makimura, K. (2017). Clinical evaluation of $\beta$-tubulin real-time PCR for rapid diagnosis of dermatophytosis, a comparison with mycological methods. Mycoses, 60(10), 692-696.

Morais, T. G., Pereira, J. M., \& Cunha, R. (2018). Morfologia de fungos isolados de um ambiente hospitalar e avaliação do conhecimento dos visitantes/acompanhantes sobre infecção hospitalar. In Anais do Congresso de Ensino, Pesquisa e Extensão da UEG (CEPE)(ISSN 2447-8687) (Vol. 4).

Morris, A. J., Arthur, I. H., Kidd, S. E., Halliday, C. L., Meyer, W., Robson, J. M., \& Haremza, E. (2016). Mycological testing of clinical samples in Australasian pathology laboratories: wide diversity and room for improvement. Pathology, 48(6), 531-534.

Oliveira, A. R., Cintra, J., Pereira, L., Pires, R. H., \& Dias, F. (2015). Incidência de dermatófitos em felinos atendidos no hospital veterinário da universidade de franca (UNIFRAN-SP). Enciclopédia biosfera, 11(22).

Pereira A. S. et al. (2018). Metodologia da pesquisa científica. UFSM. https://repositorio.ufsm.br/bitstream/handle/1/15824/Lic_Computacao_MetodologiaPesquisa-Cientifica.pdf?sequence $=1$.

Pereira, L. F. S., Neves, A. D. C., Fontes, M. L. A., Brabo, G. L. C., Lino, R. M., Trindade, E. L., \& Bezerra, N. V. (2019). Avaliação da presença de fungos no ar, água e areia de duas praias de Outeiro, Pará, Brasil. Brazilian Journal of Health Review, 2(5), 4174-4187.

Pereira, R. S., Santos, H. D. H., Moraes, O. S., Júnior, D. P. L., \& Hahn, R. C. (2020). Children's public health: Danger of exposure to pathogenic fungi in recreational places in the middle-west region of Brazil. Journal of infection and public health, 13(1), 51-57.

Rezaei-Matehkolaei, A., Khodavaisy, S., Alshahni, M. M., Tamura, T., Satoh, K., Abastabar, M., Badali, H. (2018). In vitro antifungal activity of novel triazole efinaconazole and five comparators against dermatophyte isolates. Antimicrobial agents and chemotherapy, 62(5).

Ribeiro, C. S. D. C., Zaitz, C., Framil, V. M. D. S., Ottoboni, T. S. D. C., Tonoli, M. S. D. C., \& Ribeiro, R. P. (2015). Descriptive study of onychomycosis in a hospital in São Paulo. Brazilian Journal of Microbiology, 46(2), 485-492.

Rodrigues, D. A., Tomimori, J., Floriano, M. C., \& Mendonça, S. (2010). Atlas de dermatologia em povos indígenas. SciELO-Editora Fap-Unifesp.

Sidrim, J. J., Rocha, M. F. G. (2012). Micologia à Luz dos Autores Contemporâneos. Ed. Guanabara Koogan. Guanabara Koogan, $157-167$.

Silva-Rocha, W. P., Azevedo, M. F., \& Chaves, G. M. (2017). Epidemiology and fungal species distribution of superficial mycoses in Northeast Brazil. Journal de mycologie medicale, 27(1), 57-64.

Silva, C. S. (2019). Etiologia e epidemiologia da tinea capitis: relato de série de casos e revisão da literatura. $R B A C, 51(1), 9-16$.

Silva, K. A. D., Gomes, B. S., Magalhães, O. M. C., \& Lacerda Filho, A. M. (2018). Etiologia das dermatofitoses diagnosticadas em pacientes atendidos no Laboratório de Micologia Médica no Centro de Biociências da Universidade Federal de Pernambuco, entre 2014-2017. Rev Bras Analises Clin, 50(1), 33-7.

Song, X., Wei, Y. X., Lai, K. M., He, Z. D., \& Zhang, H. J. (2018). In vivo antifungal activity of dipyrithione against Trichophyton rubrum on guinea pig dermatophytosis models. Biomedicine \& Pharmacotherapy, 108, 558-564.

Xiao, Y., Hu, Q., Jiao, L., Cui, X., Wu, P., He, P., \& Zhao, S. (2019). Production of anti-Trichophyton rubrum egg yolk immunoglobulin and its therapeutic potential for treating dermatophytosis. Microbial pathogenesis, 137, 103741. 